\title{
Inhibitory effect and mechanisms of microRNA-146b-5p on the proliferation and metastatic potential of Caski human cervical cancer cells
}

\author{
CUIPING SHEN ${ }^{1}$, HUI YANG ${ }^{2}$, HONG LIU ${ }^{2}$, XIUQIN WANG ${ }^{2}$, YOUZHONG ZHANG ${ }^{1}$ and RUI XU ${ }^{2}$ \\ ${ }^{1}$ Department of Gynecology and Obstetrics, Qilu Hospital, Shandong University, Jinan, Shandong 250012; \\ ${ }^{2}$ Department of Gynecology and Obstetrics, Rizhao People's Hospital, Rizhao, Shandong 276826, P.R. China
}

Received February 15, 2014; Accepted November 19, 2014

DOI: $10.3892 / \mathrm{mmr} .2015 .3151$

\begin{abstract}
Cervical cancer is a common cause of cancer-associate mortality in females, and metastasis is strongly associated with failure of cervical cancer treatment. Previous studies have indicated that microRNA (miR)-146b-5p is involved in the inhibition of proliferation and metastasis of numerous human cancer types. The aim of the present study was to explore the inhibitory effect of miR-156b-5p on the proliferation and metastatic potential of Caski human cervical cancer cells, as well as to determine the mechanisms by which it proceeds. The results demonstrated that miR-146b-5p was able to inhibit the proliferative, invasive and adhesive potential and block the cell cycle progression of Caski human cervical cancer cells, as determined using MTS and transwell assays as well as flow cytometry. Furthermore, quantitative polymerase chain reaction and western blot analysis revealed that transfection with miR-146b-5p decreased the mRNA and protein expression levels of $\mathrm{C}-\mathrm{X}-\mathrm{C}$ chemokine receptor type 4, matrix metalloproteinase-2 and -9 , c-Myc, cyclin D1 and human papilloma virus 16. In addition, the secretion levels of transforming growth factor- $\beta$, monocyte chemoattractant protein- 1 and tumor necrosis factor- $\alpha$, the telomerase activity, the phosphorylation of c-Jun N-terminal protein kinase and protein kinase $\mathrm{B}$ and the transcriptional activities of nuclear factor- $\mathrm{\kappa B}$, signal transducer and activator of transcription-3 and -5 were reduced. However, increased levels of p27 and p53 were detected in the miR-146b-5p-overexpressing Caski cells. These results indicate that miR-146b-5p may be a potential therapeutic strategy for the treatment of cervical cancer through regulation of cell chemotaxis and the cell cycle.
\end{abstract}

Correspondence to: Mr. Youzhong Zhang, Department of Gynecology and Obstetrics, Qilu Hospital, Shandong University, 107 Wenhua Western Road, Jinan, Shandong 250012, P.R. China E-mail: youzhong_zhangsd@126.com

Key words: human cervical cancer, microRNA-146b-5p, metastasis

\section{Introduction}

Cervical cancer is a common malignancy in females, which is associated with a severe risk of cancer-associated mortality. The etiology and pathogenesis of cervical cancer are not yet fully understood (1). However, increased risk is considered to be associated with marriage at a young age, multiparity, cervical laceration, poor local hygiene and numerous other factors. In the past two decades, the viral etiology of cervical cancer has received increasing attention (2). Human papilloma virus (HPV) infection is considered to be an important pathogenic risk factor for cervical cancer (3). Currently, surgery remains the most effective treatment option for cervical cancer. However, upon development of infiltrating lesions, the disease progresses very rapidly and often results in mortality within $2-5$ years if untreated $(4,5)$. Therefore, the occurrence of tumor metastasis often causes failure of cervical cancer treatment (6).

With recent advances in oncological research, microRNA (miRNA/miR) has attracted interest among researchers as a potential biotherapy. miRNAs are a class of endogenous, small-molecule, non-coding, single-stranded RNAs, which are 19-24 nucleotides (nt) long (7). miRNAs have been shown to be highly conserved during evolution. The specific complementary pairing of miRNAs with the bases of target gene mRNA, may result in the degradation or inhibition of the target gene mRNA translation, leading to widespread negative regulation of target gene expression (8). Currently, >400 miRNAs have been identified, which have the ability to regulate the expression levels of one third of the genes in the human body (9). Mutations of miRNA can activate the expression of associated oncogenes or inhibit the expression of tumor suppressor genes, leading to carcinogenesis (10).

To date, the role of miRNAs in cancer progression remains unclear. A previous study demonstrated that miR-146b-5p is able to inhibit the growth and metastasis of various types of cancer (11). The present study investigated the inhibitory effects and mechanisms of miR-146b-5p on the proliferation and metastatic potential of Caski human cervical cancer cells. The aim was to determine a novel direction for cancer biotherapy and provide a potential target for the prevention and determination of cancer metastasis. 


\section{Materials and methods}

Cells and cell culture. The Caski human cervical cancer cell line (American Type Culture Collection, Manassas, VA, USA) was routinely subcultured in Dulbecco's modified Eagle's medium (Corning Life Sciences, Manassas, VA, USA) supplemented with $10 \%$ fetal bovine serum (FBS; Corning Life Sciences), $100 \mathrm{U} / \mathrm{ml}$ penicillin and $100 \mathrm{U} / \mathrm{ml}$ streptomycin (Sigma-Aldrich, St. Louis, MO, USA) at $37^{\circ} \mathrm{C}$, in a humidified atmosphere containing $5 \% \mathrm{CO}_{2}$. Upon reaching $80 \%$ confluence, the cells were digested with $0.25 \%$ trypsin, followed by repetitive pipetting to disperse the cells into a single-cell suspension for routine subculture. The present study was approved by the ethics committee of Qilu Hospital of Shandong University (Jinan, China).

The expression plasmid, pGPU6/Neo-miR-146b-5p, and the nonsense scrambled sequence, pGPU6/Neo-NC, were purchased from Shanghai GenePharma Co., Ltd. (Shanghai, China). The cells $\left(3 \times 10^{5}\right)$ were seeded into six-well plates and cultured for $24 \mathrm{~h}$ at $37^{\circ} \mathrm{C}$ with $5 \% \mathrm{CO}_{2}$, followed by transfection with the pGPU6/Neo-miR-146b-5p or pGPU6/Neo-NC plasmids, using Lipofectamine ${ }^{\circledR} 2000$ (Invitrogen Life Technologies, Carlsbad, CA, USA), according to the manufacturer's instructions. To establish the stable sub-cell lines, the cells were screened with 200 mg/l G418 (Sigma-Aldrich). Untreated Caski cells were considered as the control group, Caski cells transfected with pGPU6/Neo-NC were the negative group and Caski cells transfected with pGPU6/Neo-miR-146b-5p were the miR-146b-5p group. The expression of miR-146b-5p was quantified using stem-loop quantitative polymerase chain reaction (qPCR), with U6 as the internal control (12).

MTS cell proliferation assay. A total of $2 \times 10^{3}$ cells were seeded into 96 -well plates and cultured at $37^{\circ} \mathrm{C}$ for $24 \mathrm{~h}$ in an atmosphere containing $5 \% \mathrm{CO}_{2}$. Fresh culture medium and $20 \mu \mathrm{l}$ MTS solution (Promega Corp., Madison, WI, USA) were then added to each well and cultured for $2 \mathrm{~h}$. The absorbance was detected at $490 \mathrm{~nm}$ using a microplate reader (iMark; Bio-Rad Laboratories, Inc., Hercules, CA, USA). A cell growth curve was then generated with time as the abscissa and the absorbance value as the ordinate.

Transwell invasion assay. The bottom of transwell chambers was coated with $60 \mu \mathrm{l}$ Matrigel (BD Biosciences, Franklin Lakes, NJ, USA). A total of $5 \times 10^{5}$ cells in $200 \mu 1$ serum-free culture medium were added to the upper chamber and $600 \mu \mathrm{l}$ complete culture medium, containing $10 \%$ FBS, was added to the lower chamber that was pre-coated with $10 \mu \mathrm{g} / \mathrm{ml}$ fibronectin (Sigma-Aldrich). Next, the samples were incubated for $24 \mathrm{~h}$ at $37^{\circ} \mathrm{C}$ and $5 \% \mathrm{CO}_{2}$. The chamber membranes were then stained with crystal violet (Sigma-Aldrich) at room temperature for $25 \mathrm{~min}$ and washed three times with phosphate-buffered saline (PBS). Subsequently, the cells of four randomly selected central and peripheral visual fields were counted (BX53; Olympus Corp., Tokyo, Japan).

Cell adhesion assay. A total of $5 \times 10^{4}$ cells were seeded into a 96-well plate that was pre-coated with Matrigel and incubated at $37^{\circ} \mathrm{C}$ in a $5 \% \mathrm{CO}_{2}$ incubator for $3 \mathrm{~h}$. The cells were then stained with $0.1 \%$ crystal violet for $25 \mathrm{~min}$ and washed five times with PBS. Subsequently, $100 \mu 110 \%$ acetic acid was added to each well and the cells were lysed for $10 \mathrm{~min}$. The absorbance values of the samples were detected at $570 \mathrm{~nm}$ using a microplate reader.

Cell cycle determination. To investigate the cell cycle, $3 \times 10^{5}$ cells were seeded into 6 -well plates and incubated at $37^{\circ} \mathrm{C}$ in a $5 \% \mathrm{CO}_{2}$ incubator for $24 \mathrm{~h}$. Following digestion with $0.25 \%$ Trypsin (Sigma-Aldrich) and centrifugation at $500 \mathrm{x} \mathrm{g}$ for $5 \mathrm{~min}, 70 \%$ pre-cooled ethanol was added to the cells, which were fixed at $4{ }^{\circ} \mathrm{C}$ overnight. Next, the samples were centrifuged and the ethanol solution was discarded, followed by staining with propidium iodide (Sigma-Aldrich) containing DNaseA (Beyotime, Shanghai, China) for $30 \mathrm{~min}$ in the dark. The distribution of cells in the cell cycle was then determined using a flow cytometer (FACSAria; BD Biosciences).

qPCR. A total of $3 \times 10^{5}$ cells were seeded into 6-well plates and incubated at $37^{\circ} \mathrm{C}$ in an atmosphere containing $5 \% \mathrm{CO}_{2}$ for $24 \mathrm{~h}$. Total RNA (200 ng/ $\mu \mathrm{l})$ was extracted from the cells using TRIzol ${ }^{\circledR}$ reagent (Invitrogen Life Technologies). RNA was then reverse transcribed into cDNA, according to the manufacturer's instructions of the RNA reverse transcription kit (Invitrogen Life Technologies). cDNA was mixed with ABI SYBR ${ }^{\circledR}$ Green Master Mix (Applied Biosystems Life Technologies, Foster City, NJ, USA) and specific gene primers, followed by amplification using an ABI 7500 Real-time PCR system (Applied Biosystems Life Technologies). The primer sequences (Invitrogen Life Technologies) used were as follows: C-X-C chemokine receptor type 4 (CXCR4) forward, 5'-ATCTTCCTGCCCACCATCTACTCCATCATC-3', and reverse, 5'-ATCCAGACGCCAACATAGACCACCTTT TCA-3'; matrix metalloproteinase (MMP)-2 forward, 5'-TGA TGGTGTCTGCTGGAAAG-3', and reverse, 5'-GACACG TGAAAAGTGCCTTG-3'; MMP-9 forward, 5'-GCCTTT GGACACGCACG-3', and reverse, 5'-AGCGGTCCTGGC AGAAATAG-3'; c-Myc forward, 5'-TACCCTCTCAACGAC AGCAG-3', and reverse, 5'-TCTTGACATTCTCCTCGG TG-3'; cyclin D1 forward, 5'-TCTAAGATGAAGGAGACC ATC-3', and reverse, 5'-GCGGTAGTAGGACAGGAAGTT GTT-3'; human papilloma virus (HPV)16 forward, 5'-GTC AAAAGCCACTGTGTCCT-3', and reverse, 5'-CCATCC ATTACATCCCGAC-3'; p27 forward, 5'-CAAGTACGAGTG GCAAGAGG-3', and reverse, 5'-GTAGAAGAATCGTCG GTTGC-3'; and p53 forward, 5'-AACCTACCAGGGCAG CTACG-3', and reverse 5'-TTCCTCTGTGCGCCGGTCTC-3'. The results were normalized to GAPDH forward, 5'-GCA GGGGGGAGCCAAAAGGG-3', and reverse, 5'-TGCCAG CCCCAGCGTCAAAG-3'. Amplification conditions were as follows: Pre-denaturation at $94^{\circ} \mathrm{C}$ for $5 \mathrm{~min}$, followed by 40 cycles of $95^{\circ} \mathrm{C}$ for $5 \mathrm{~min}$ and $65^{\circ} \mathrm{C}$ for $40 \mathrm{sec}$. Results were quantified using MJ Opticon Monitor Software 3.1 (Bio-Rad Laboratories, Inc.).

Western blot analysis. To perform western blot analysis, $3 \times 10^{5}$ cells were seeded into 6 -well plates and incubated at $37^{\circ} \mathrm{C}$ in an atmosphere containing $5 \% \mathrm{CO}_{2}$ for $24 \mathrm{~h}$. Pre-cooled lysis buffer (Millipore, Billerica, MA, USA) was then added to isolate the protein from the cells and the samples were centrifuged at $10,000 \mathrm{x}$ g at $4^{\circ} \mathrm{C}$ for $20 \mathrm{~min}$. The protein concentrations 
were determined using the Bradford method (13). Total protein $(80 \mu \mathrm{g})$ was separated on a $12 \%$ polyacrylamide gel (Pierce Biotechnology, Inc., Rockford, IL, USA) and transferred onto polyvinylidene fluoride membranes (Millipore). Next, the membranes were blocked in 5\% skim milk at room temperature for $1 \mathrm{~h}$, and incubated with the following primary mouse anti-human monoclonal antibodies: CXCR4, MMP-2, MMP-9, c-Myc, cyclin D1, p27, p53, phospho (p)-protein kinase B (Akt) and p-c-Jun N-terminal protein kinase (JNK), which were all purchased from Santa Cruz Biotechnology, Inc. (Dallas, TX, USA) at a dilution of 1:500, as well as $\beta$-actin $(1: 5,000$; Sigma-Aldrich) at $4^{\circ} \mathrm{C}$ overnight. The membranes were washed three times with Tris-buffered saline/Tween 20 (TBST) and then incubated with horseradish peroxidase-conjugated secondary immunoglobulin $\mathrm{G}$ antibodies $(1: 5,000)$ at room temperature for $30 \mathrm{~min}$. Subsequently, the membranes were washed a further three times with TBST and treated with an enhanced chemiluminescence reagent (Millipore) for 1-2 min, prior to exposure to an X-ray film (SDT Film Co., Ltd., Suzhou, China). The results were normalized to $\beta$-actin.

Telomerase activity assay. For determination of the telomerase activity, $3 \times 10^{5}$ cells were seeded into 6 -well plates and incubated at $37^{\circ} \mathrm{C}$ in a $5 \% \mathrm{CO}_{2}$ incubator for $24 \mathrm{~h}$. Pre-cooled lysis buffer was then added and the cells were centrifuged at $10,000 \mathrm{x} g$ at $4^{\circ} \mathrm{C}$ for $20 \mathrm{~min}$. Next, the protein concentrations were determined using the Bradford method. Total protein $(2 \mu \mathrm{g})$ was used to perform a telomerase activity assay using the TeloTAGGG Telomerase PCR ELISA (Roche Diagnostics, Basel, Switzerland), according to the manufacturer's instructions. The PCR reaction conditions were set at: $25^{\circ} \mathrm{C}$ for $20 \mathrm{~min} ; 94^{\circ} \mathrm{C}$ for $5 \mathrm{~min} ; 30$ cycles at $94^{\circ} \mathrm{C}$ for $30 \mathrm{sec}, 50^{\circ} \mathrm{C}$ for $30 \mathrm{sec}$ and $72^{\circ} \mathrm{C}$ for $90 \mathrm{sec}$; and $72^{\circ} \mathrm{C}$ for $10 \mathrm{~min}$. PCR ELISA was performed using the PCR products $(5 \mu \mathrm{l})$ to detect the telomerase activity at $450 \mathrm{~nm}$ using a microplate reader (Bio-Rad Laboratories, Inc.).

ELISA. In total, $3 \times 10^{5}$ cells were seeded into 6-well plates and incubated at $37^{\circ} \mathrm{C}$ in a $5 \% \mathrm{CO}_{2}$ incubator for $24 \mathrm{~h}$. Following the 24-h culture, the culture medium was replaced with serum-free culture medium and the cells were cultured for a further $24 \mathrm{~h}$. The supernatants were collected through centrifugation at $300 \mathrm{x} \mathrm{g}$ for $10 \mathrm{~min}$ and the concentrations of the transforming growth factor (TGF)- $\beta$ (human TGF- $\beta 1$ Quantikine ELISA kit), monocyte chemoattractant protein (MCP)-1 (human MCP-1 Quantikine ELISA kit) and tumor necrosis factor (TNF)- $\alpha$ (human TNF- $\alpha$ Quantikine ELISA kit) were measured using ELISA kits (R\&D Systems, Inc., Minneapolis, MN, USA), according to the manufacturer's instructions.

Dual luciferase report assay. The cells were transfected with $2 \mu \mathrm{g}$ nuclear factor (NF)- $\mathrm{B}$, signal transducer and activator of transcription (STAT)3 and STAT5 fluorescent reporter plasmid or $0.02 \mu \mathrm{g}$ control plasmid (Beyotime) were transfected using Lipofectamine 2000 (Invitrogen Life Technologies) for $24 \mathrm{~h}$. Subsequently, the luciferase activity of the cells was detected using a Dual Luciferase ${ }^{\circledR}$ Reporter assay, according to the manufacturer's instructions.

Statistical analysis. SPSS version 13.0 software (SPSS Inc., Chicago, IL, USA) was used for statistical analyses. The experimental data are presented as the mean \pm standard deviation and the statistical significance of differences between the groups was determined using a one-way analysis of variance. $\mathrm{P}<0.05$ was considered to indicate a statistically significant difference.

\section{Results}

Effect of miR-146b-5p on the biological characteristics of Caski cells. Increased expression levels of miR-146b-5p were observed in the miR-146b-5p group, when compared with the control and negative groups, as determined by qPCR (Fig. 1A). Based on the results of the MTS assay, the 120-h relative proliferation rate in the miR-146b-5p group was found to be $62.4 \%$ of the control group rate $(\mathrm{P}<0.05)$. Therefore, transfection with miR-146b-5p was able to significantly inhibit the proliferation of Caski cells in vitro (Fig. 1B). In addition, the results of the transwell assay demonstrated that transfection with miR-146b-5p was found to significantly inhibit the invasion of Caski cells in vitro, since the cell invasion rate in the miR-146b-5p group was $23.5 \%$ that of the control group $(\mathrm{P}<0.05)$ (Fig. 1C). Furthermore, transfection with miR-146b-5p significantly inhibited the adhesion of Caski cells in vitro, since the cell adhesion rate in the miR-146b-5p group was $43.5 \%$ that of the control group $(\mathrm{P}<0.05)$ (Fig. 1D). In addition, the percentage of cells in the $G_{0} / G_{1}$ phase of the cell cycle was found to be significantly increased in the miR-146b-5p group, indicating that miR-146b-5p was capable of arresting the Caski cells in the cell cycle (Fig. 1E).

Effect of miR-146b-5p on cytokine secretion and telomerase activity of Caski cells. As determined by ELISA, transfection with miR-146b-5p was able to significantly inhibit the secretion levels of TGF- $\beta$, MCP-1 and TNF- $\alpha$ in Caski cells. The secretion levels of TGF- $\beta$, MCP-1 and TNF- $\alpha$ in the miR-146b-5p group was $42.7,51.2$ and $63.8 \%$ that of the control group, respectively $(\mathrm{P}<0.05)$ (Fig. $2 \mathrm{~A})$. In addition, transfection with miR-146b-5p was found to significantly inhibit the telomerase activity of Caski cells, as determined by qPCR analysis. The telomerase activity in the miR-146b-5p group was $62.8 \%$ that of the control group $(\mathrm{P}<0.05)$ (Fig. 2B).

Effect of miR-146b-5p on Caski cell proliferation and metastasis-associated gene expression. As demonstrated by western blot analysis, transfection with miR-146b-5p significantly inhibited the protein expression levels of CXCR4, MMP-2, MMP-9, c-Myc, cyclin D1 and HPV16, while it increased the protein expression levels of p27 and p53 in the Caski cells (Fig. 3A). Furthermore, the mRNA expression levels of CXCR4, MMP-2, MMP-9, c-Myc, cyclin D1, HPV16, p27 and p53 in the miR-146b-5p group were found to be $38.4,27.2,21.1,22.7,18.6,43.6,267.3$ and $255.0 \%$ that of the control group $(\mathrm{P}<0.05)$, respectively, as determined by qPCR (Fig. 3B). These results indicated that miR-146b-5p was capable of modifying the biological characteristics of tumor cells by regulating tumor cell proliferation and the expression levels of metastasis-associated genes.

Effect of miR-146b-5p on the signal transduction pathway of Caski cells. Western blot analysis demonstrated that 
A

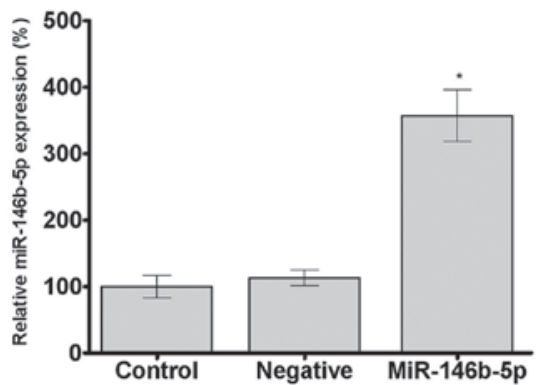

C
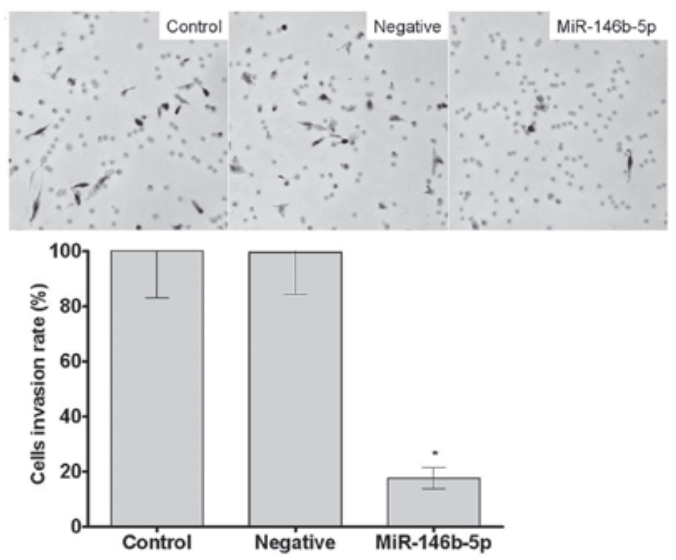

$\mathbf{E}$

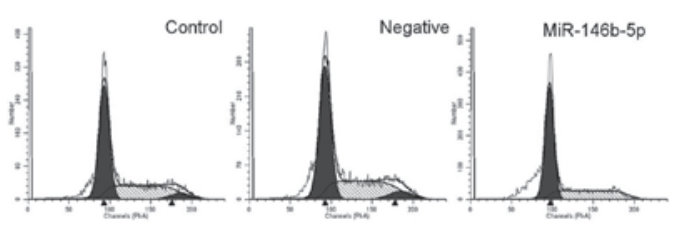

B

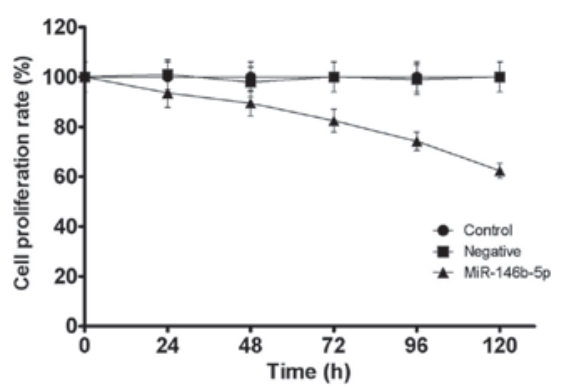

D
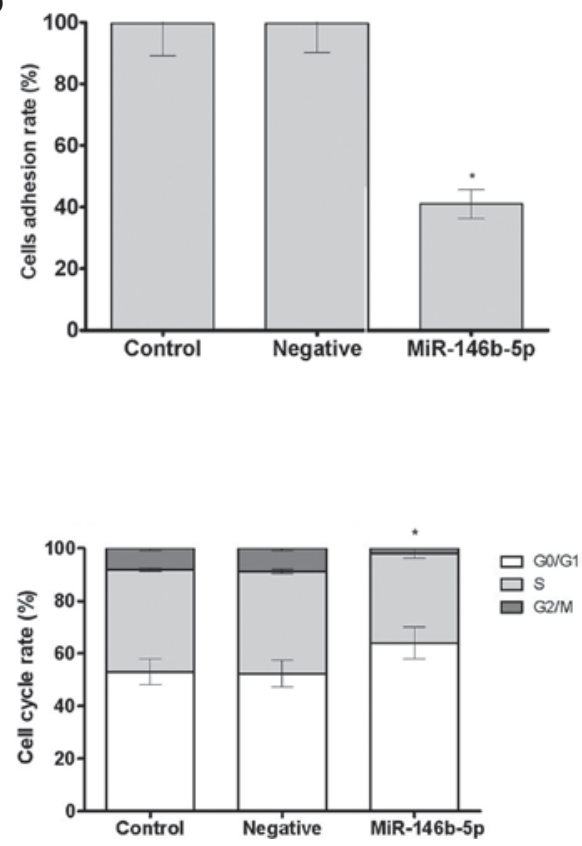

Figure 1. Effect of miR-146b-5p on the biological characteristics of Caski human cervical cancer cells. (A) Quantitative polymerase chain reaction indicated increased expression levels of miR-146b-5p in the miR-146b-5p group, when compared with the control and negative groups ( $\mathrm{n}=5$ ). (B) MTS assay demonstrated a decreased rate of cell proliferation in the miR-146b-5p group, when compared with the control and negative groups ( $\mathrm{n}=5$ ). (C) Transwell assay revealed a decreased rate of cell invasion in the miR-146b-5p group, when compared with the control and negative groups ( $\mathrm{n}=3$ ). (D) Adhesion assay revealed a decreased rate of cell adhesion in the miR-146b-5p group, when compared with the control and negative groups ( $\mathrm{n}=5$ ). (E) Flow cytometric analysis revealed an increased percentage of cells in the $G_{0} / G_{1}$ phase in the miR-146b-5p group, when compared with the control and negative groups ( $n=3$ ). All the data are presented as the mean \pm standard deviation from at least three independent experiments. ${ }^{*} \mathrm{P}<0.05$, vs. control group. miR, microRNA.

A

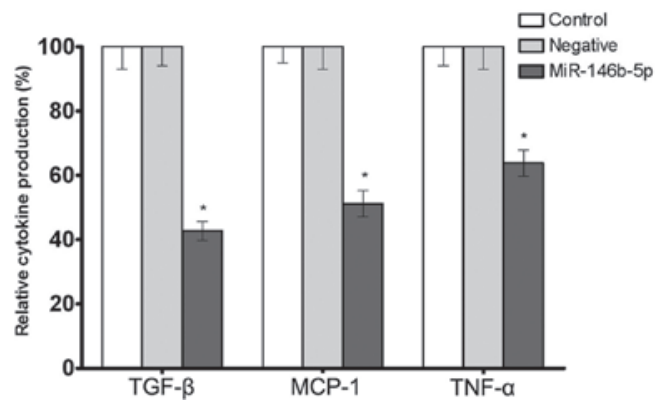

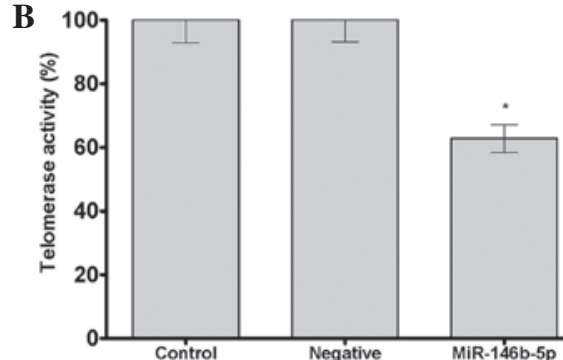

Figure 2. Effect of miR-146b-5p on cytokine secretion and telomerase activity of Caski human cervical cancer cells. ELISA revealed (A) a decreased production of transforming growth factor (TGF)- $\beta$, monocyte chemoattractant protein (MCP)-1 and tumor necrosis factor (TNF)- $\alpha$ and (B) decreased telomerase activity in the miR-146b-5p group, compared with the control and negative groups $(n=5)$. All the data are presented as the mean \pm standard deviation from at least three independent experiments. " $\mathrm{P}<0.05$, vs. control group. miR, microRNA.

transfection with miR-146b-5p significantly inhibited the phosphorylation of Akt and JNK in Caski cells (Fig. 4A). Furthermore, a dual luciferase reporter assay indicated that the transcriptional activities of NF-кB, STAT3 and STAT5 in the miR-146b-5p group were $36.3,52.4$ and $38.5 \%$ that of the control group, respectively $(\mathrm{P}<0.05)$ (Fig. 4B). These 
A

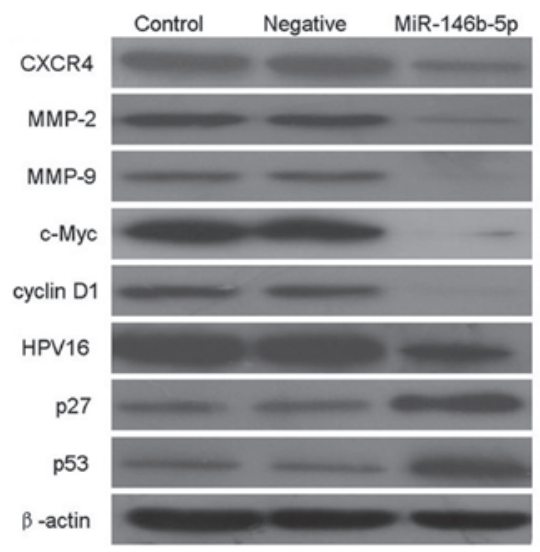

B

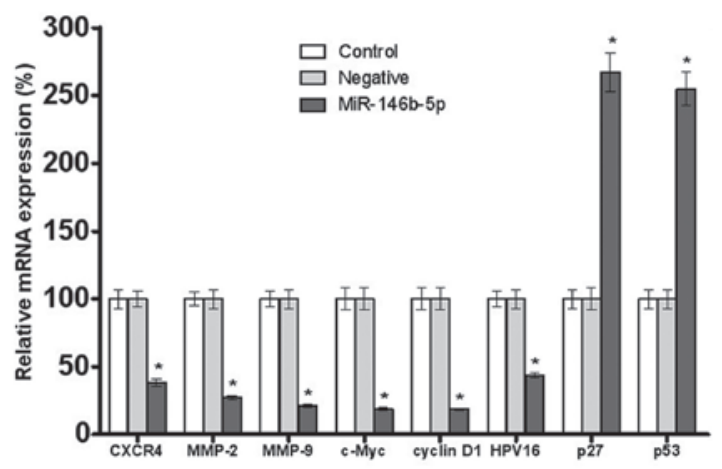

Figure 3. Effects of miR-146b-5p on proliferation and metastasis-associated gene expression of Caski human cervical cancer cells. (A) Protein expression levels, determined by western blot analysis (using $\beta$-actin as an internal loading control), and (B) mRNA expression levels, determined by quantitative polymerase chain reaction (using GAPDH as an internal loading control). The protein and mRNA expression levels of CXCR4, MMP-2 and 9, c-Myc, cyclin D1 and HPV16 were found to be decreased, whereas the protein and mRNA expression levels of p27 and p53 were found to be increased, in the miR-146b-5p group when compared with the control and negative groups. All the data are presented as the mean \pm standard deviation from at least three independent experiments. ${ }^{*} \mathrm{P}<0.05$, vs. control group. miR, microRNA; CXCR4, C-X-C chemokine receptor type 4; MMP, matrix metalloproteinase; HPV, human papilloma virus.

A

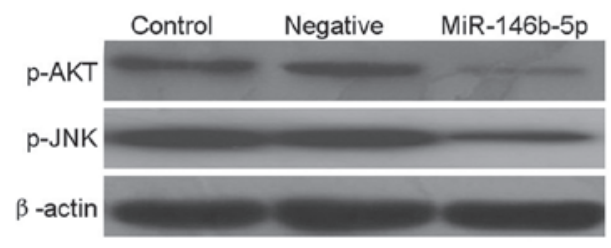

B

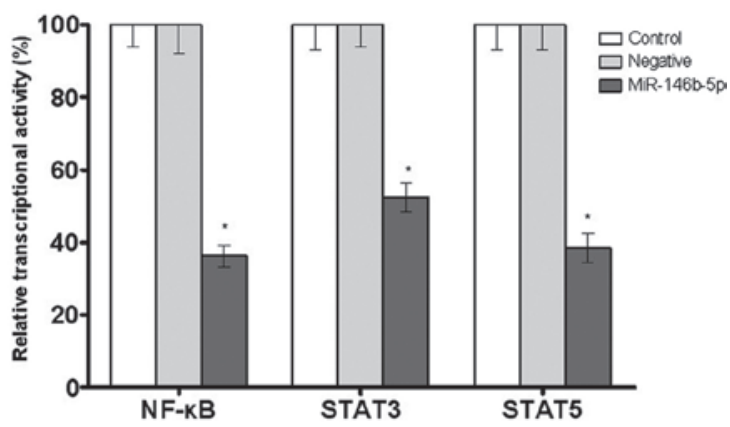

Figure 4. Effect of miR-146b-5p on the signal transduction pathway of Caski human cervical cancer cells. (A) Western blot assay revealed decreased phosphorylation of Akt and JNK in the miR-146b-5p group, when compared with the control and negative groups. $\beta$-actin was used as an internal loading control. (B) Dual luciferase reporter assay revealed decreased transcriptional activity of NF- $\kappa \mathrm{B}$, STAT3 and 5 in the miR-146b-5p group, when compared with control and negative groups. All the data are presented as the mean \pm standard deviation from at least three independent experiments ( $\mathrm{n}=5$ ). ${ }^{*} \mathrm{P}<0.05$, vs. control group. miR, microRNA; Akt, protein kinase B; JNK, c-Jun N-terminal protein kinase; NF, nuclear factor; STAT, signal transducer and activator of transcription.

results indicated that miR-146b-5p was capable of modifying the biological characteristics of tumor cells by regulating the activity of tumor cell signal transduction molecules (Fig. 4).

\section{Discussion}

Cervical cancer is one of the most common cancers in females. Although surgery is the primary treatment strategy for cervical cancer, tumor metastasis often leads to poor therapeutic efficacy. Therefore, research on the identification of cervical cancer metastasis inhibitors has received increasing attention. Tumor cell metastasis is a complex process that involves numerous factors, and the underlying mechanisms include enhanced heterotypic cell-cell adhesion, upregulated MMP expression and increased secretion of pro-metastatic cytokines (14).

Tumor-associated genes, including CXCR4, matrix metalloproteinase-2/9, c-Myc, cyclin D1, p27 and p53 have important roles in proliferation and metastasis (15). Tumor invasion and metastasis are often associated with the upregulation of CXCR4 expression, which is an important chemotactic factor. CXCR4 can improve the chemotactic activity of tumor cells, enabling their invasion and migration to surrounding tissues during the process of tumor metastasis. In addition, the upregulation of CXCR4 expression has been shown to be directly correlated with tumor invasion and metastasis (16). MMPs are involved in the degradation of the extracellular matrix (ECM) and basilar membrane, as well as in numerous physiological and pathological processes. In addition, MMPs are important regulatory molecules involved in tumor infiltration, metastasis and angiogenesis, and therefore play a key role in tumor progression (17). MMP-2 is a zinc-dependent protease, with substrates including types IV, VII and X collagen and gelatin, which are the main components of the ECM and vascular basilar membrane. Overexpression of MMP-2 accelerates the degradation of the ECM and vascular basilar membrane, enabling the tumor cells to migrate from tumor nests and across blood vessels, therefore facilitating tumor invasion and metastasis. Overexpression of MMP-2 is associated with the enhanced invasive and metastatic capacity of numerous tumors (18). MMP-9 is one of the most important proteases capable of degrading the basilar membrane within the MMP enzyme family. MMP-9 is initially secreted as a zymogen by the cells, which can induce enzymolysis following activation 
by various factors. Enzymolysis of the ECM enhances tumor growth into the surrounding area. Numerous studies have observed fairly high expression levels of MMPs in various tumor tissues, including nasopharyngeal carcinoma, and these expression levels have been found to be associated with tumor invasiveness (19).

Previous studies have demonstrated that p27 and p53 genes control cell death and proliferation and also limit the metastatic capability of cancer cells, by regulating the expression levels of oncogenes (20). Therefore, the loss of p27 and p53 greatly enhances tumor progression and metastasis, while the lack of p27 and p53 expression has been shown to be directly correlated with tumor invasion and metastasis $(21,22)$. In tumor cells, the proteins that control progression of the cell cycle, such as cyclins, are often overexpressed; by contrast, the proteins that suppress cell division, such as cyclin-dependent kinase (CDK) inhibitors, are often inactivated. Among the numerous cell cycle regulatory factors, cyclin D1 is significant. Cyclin D1 forms a complex with $\mathrm{CDK}_{4} / 6$ in $\mathrm{G}_{1}$ phase, thereby driving cells from $\mathrm{G}_{1}$ to $\mathrm{S}$ phase and causing cell division or conversion. A previous study has reported that overexpression of cyclin D1 was detected in lung, breast, thyroid and prostate cancer tissues, as well as in other tumors, thus indicating a certain association between cyclin D1 and tumorigenesis (23).

Telomerase activity has been previously demonstrated to be associated with tumor metastatic potential, due to shortened telomeres (24). The present study aimed to determine the role of telomerase activity on the ability of miR-146b-5p to inhibit metastasis of Caski cells. The results indicated that telomerase activity was decreased in Caski cells overexpressing miR-146b-5p. In addition, the present study provided evidence regarding a potential mechanism for miR-146b-5p-inhibited metastasis of Caski cells. Human papilloma virus (HPV) is also an important factor in cervical carcinogenesis and cancer progression, while HPV16 is considered to be the most common high-risk type of HPV. HPV16 E7 participates in the tumorigenesis of the majority of cervical cancers. Extensive clinical and pathological studies have confirmed that HPV16 E7 expression is closely correlated with poor tumor differentiation, susceptibility to lymph node metastasis and poor prognosis in oral, breast and gastric cancer, as well as in various other human epithelial malignancies $(25,26)$. Previous studies have also observed an upregulation of TGF- $\beta$, MCP-1 and TNF- $\alpha$ expression in HPV16-infected malignant tumor tissues, which was considered to be associated with tumor metastasis, signal transduction pathways and the upregulation of the expression of proliferation-associated regulatory factors (27).

Akt is a downstream effector molecule in the phosphoinositide 3-kinase signaling pathway, the most important target enzyme of which is JNK. JNK is frequently detected during carcinogenesis and the progression of malignant tumors. The phosphorylation of Akt and JNK, as well as the activity of NF- $\mathrm{B}, \mathrm{STAT} 3$ and STAT5, play an important role in the signaling pathways of tumor invasion and metastasis, through a series of substrate phosphorylation $(28,29)$. These pathways can regulate the expression levels of CXCR4, MMP-2, MMP-9 and other oncogenes and may also participate in tumor cell invasion and migration.

In conclusion, the present study demonstrated that miR-146b-5p was able to inhibit the in vitro proliferative, adhesive and invasive ability of tumor cells, and arrest the cell cycle in $\mathrm{G}_{0} / \mathrm{G}_{1}$ phase in Caski cells. In addition, transfection with miR-146b-5b was hypothesized to be associated with the downregulation of CXCR4, MMP-2, MMP-9, c-Myc, cyclin D1 and telomerase activity, the upregulation of $\mathrm{p} 27$ and $\mathrm{p} 53$, the inhibition of TGF- $\beta, \mathrm{MCP}-1, \mathrm{TNF}-\alpha$ and other cytokine secretions, and the inhibition of Akt phosphorylation and transcriptional activity of NF- $\mathrm{NB}$, STAT3 and STAT5. Furthermore, miR-146b-5p was able to downregulate HPV16 E7 expression in the Caski cervical cancer cells, thereby laying the experimental basis for further studies of cervical cancer gene therapy.

\section{References}

1. Sriplung H, Singkham P, Iamsirithaworn S, Jiraphongsa C and Bilheem S: Success of a cervical cancer screening program: trends in incidence in songkhla, southern Thailand, 1989-2010, and prediction of future incidences to 2030. Asian Pac J Cancer Prev 15: 10003-10008, 2014

2. Üreyen I, Aksoy Ü, Dündar B, Tapisiz ÖL, Karalök MA, Turan AT, Boran N and Tulunay HG: Does lymph node involvement affect the patterns of recurrence in stage IB cervical cancer? Turk J Med Sci 44: 844-852, 2014.

3. Chawla N, Breen N, Liu B, Lee R and Kagawa-Singer M: Asian American Women in California: a pooled analysis of predictors for breast and cervical cancer screening. Am J Public Health 18: e1-e12, 2014.

4. Li C, Ma C, Zhang $\mathrm{W}$ and Wang J: The immune function differences and high-risk human papillomavirus infection in the progress of cervical cancer. Eur J Gynaecol Oncol 5: 557-561, 2014.

5. Bai LX, Wang JT, Ding L, Jiang SW, Kang HJ, Gao CF, Chen X, Chen $\mathrm{C}$ and Zhou Q: Folate deficiency and FHIT hypermethylation and HPV 16 infection promote cervical cancerization. Asian Pac J Cancer Prev 21: 9313-9317, 2014.

6. García-Zepeda SP, García-Villa E, Díaz-Chávez J, Hernández-Pando R and Gariglio P: Resveratrol induces cell death in cervical cancer cells through apoptosis and autophagy. Eur J Cancer Prev 22: 577-584, 2013.

7. Gocze K, Gombos K, Kovacs K, Juhasz K, Gocze P and Kiss I: MicroRNA expressions in HPV-induced cervical dysplasia and cancer. Anticancer Res 1: 523-530, 2015.

8. Shishodia G, Verma G, Srivastava Y, Mehrotra R, Das BC and Bharti AC: Deregulation of microRNAs Let-7a and miR-21 mediate aberrant STAT3 signaling during human papillomavirus-induced cervical carcinogenesis: role of E6 oncoprotein. BMC Cancer 14: 996, 2014.

9. Ribeiro J and Sousa H: MicroRNAs as biomarkers of cervical cancer development: a literature review on miR-125b and miR-34a. Mol Biol Rep 3: 1525-1531, 2014.

10. Wang X, Wang HK, Li Y, Hafner M, Banerjee NS, Tang S, Briskin D, Meyers C, Chow LT, et al: MicroRNAs are biomarkers of oncogenic human papillomavirus infections. Proc Natl Acad Sci USA 11: 4262-4267, 2014.

11. Kutty RK, Nagineni CN, Samuel W, Vijayasarathy C, Jaworski C, Duncan T, Cameron JE, Flemington EK, Hooks JJ and Redmond TM: Differential regulation of microRNA-146a and microRNA-146b-5p in human retinal pigment epithelial cells by interleukin- $1 \beta$, tumor necrosis factor- $\alpha$, and interferon- $\gamma$. Mol Vis 19: 737-750, 2013.

12. Li Y, Wang Y, Yu L, Sun C, Cheng D, Yu S, Wang Q, Yan Y, Kang C, Jin S, An T, Shi C, Xu J, Wei C, Liu J, Sun J, Wen Y, Zhao $\mathrm{S}$ and Kong Y: miR-146b-5p inhibits glioma migration and invasion by targeting MMP16. Cancer Lett 339: 260-269, 2013.

13. Bergot AS, Ford N, Leggatt GR, Wells JW, Frazer IH and Grimbaldeston MA: HPV16-E7 expression in squamous epithelium creates a local immune suppressive environment via CCL2- and CCL5- mediated recruitment of mast cells. PLoS Pathog 10: e1004466, 2014.

14. Yu Y, Zhang Y and Zhang S: MicroRNA-92 regulates cervical tumorigenesis and its expression is upregulated by human papilloma virus-16 E6 in cervical cancer cells. Oncol Lett 6: 468-474, 2013 
15. Zhu Y, Zhang L, Zhang GD, Wang HO, Liu MY, Jiang Y, Qi LS, Li Q and Yang P: Potential mechanisms of benzyl isothiocyanate suppression of invasion and angiogenesis by the U87MG human glioma cell line. Asian Pac J Cancer Prev 19: 8225-8228, 2014.

16. Li J, Jiang K, Qiu X, Li M, Hao Q, Wei L, Zhang W, Chen B and Xin X: Overexpression of CXCR4 is significantly associated with cisplatin-based chemotherapy resistance and can be a prognostic factor in epithelial ovarian cancer. BMB Rep 47: 33-38, 2014.

17. Nowak E, Galilejczyk A, Sypniewski D and Bednarek I: MMP-9 directed shRNAs as relevant inhibitors of matrix metalloproteinase 9 activity and signaling. Postepy Hig Med Dosw (Online) 67: 742-749, 2013.

18. Gutschalk CM, Yanamandra AK, Linde N, Meides A, Depner S and Mueller MM: GM-CSF enhances tumor invasion by elevated MMP-2, -9, and -26 expression. Cancer Med 2: 117-129, 2013.

19. Fan X, Wu W, Shi H and Han J: RNA interference targeting CD147 inhibits the invasion of human cervical squamous carcinoma cells by downregulating MMP-9. Cell Biol Int 37 737-741, 2013.

20. Zhu Y, Zhu L, Lu L, Zhang L, Zhang G, Wang Q and Yang P: Role and mechanism of the alkylglycerone phosphate synthase in suppressing the invasion potential of human glioma and hepatic carcinoma cells in vitro. Oncol Rep 1: 431-436, 2014.

21. Kuroda H, Jomen W, Miura S, Arihara Y, Yamada M, Hirako T, Abe T, Sakurai T,Fujii S, Maeda Metal: Bendamustine-rituximab therapy is effective for transformed follicular lymphoma with significant expression of p53. Gan To Kagaku Ryoho 40 1055-1058, 2013 (In Japanese).

22. Zhang M, Li J, Wang L, Tian Z, Zhang P, Xu Q, Zhang C, Wei F and Chen W: Prognostic significance of p21, p27 and survivin protein expression in patients with oral squamous cell carcinoma. Oncol Lett 6: 381-386, 2013.
23. Portari EA, Russomano FB, de Camargo MJ, Machado Gayer CR, da Rocha Guillobel HC, Santos-Rebouças CB and Brito Macedo JM: Immunohistochemical expression of cyclin D1, p16Ink4a, p21WAF1, and Ki-67 correlates with the severity of cervical neoplasia. Int J Gynecol Pathol 32: 501-508, 2013.

24. Sui X, Kong N, Wang Z and Pan H: Epigenetic regulation of the human telomerase reverse transciptase gene: A potential therapeutic target for the treatment of leukemia (Review). Oncol Lett 6: 317-322, 2013

25. Kim MS, Bak Y, Park YS, Lee DH, Kim JH, Kang JW, Song HH, Oh SR and Yoon do Y: Wogonin induces apoptosis by suppressing E6 and E7 expressions and activating intrinsic signaling pathways in HPV-16 cervical cancer cells. Cell Biol Toxicol 29: 259-272, 2013.

26. Almajhdi FN, Senger T, Amer HM, Gissmann L and Ohlschläger P: Design of a highly effective therapeutic HPV16 E6/E7-Specific DNA vaccine: Optimization by different ways of sequence rearrangements (shuffling). PLoS One 9: e113461, 2014.

27. Masuda S, Kumano K, Shimizu K, Imai Y, Kurokawa M, Ogawa S, Miyagishi M, Taira K, Hirai H and Chiba S: Notch1 oncoprotein antagonizes TGF-beta/Smad-mediated cell growth suppression via sequestration of coactivator $\mathrm{p} 300$. Cancer Sci 96: 274-282, 2005.

28. Bhaumik D, Scott GK, Schokrpur S, Patil CK, Campisi J and Benz CC: Expression of microRNA-146 suppresses NF-kappaB activity with reduction of metastatic potential in breast cancer cells. Oncogene 27: 5643-5647, 2008.

29. Geraldo MV, Yamashita AS and Kimura ET: MicroRNA miR-146b-5p regulates signal transduction of TGF- $\beta$ by repressing SMAD4 in thyroid cancer. Oncogene 31: 1910-1922, 2012. 